\title{
Model matematyczny wyboru optymalnych dróg przewozu ladunków w transporcie kolejowym
}

\begin{abstract}
W pracy przedstawiono model matematyczny wyboru optymalnych marszrut dla potoków ładunków $w$ transporcie kolejowym. Sformutowana funkcja celu zawiera dwie składowe. Pierwsza pozwala ocenić efektywność przydziału potoku do danej marszruty. Składowa druga uwzględnia efekt nieliniowy, pojawiajacy się przy zmianie potoku w danej marszrucie.
\end{abstract}

Zadanie wyboru marszruty optymalnej dla potoków ładunków w transporcie kolejowym, sprowadza się do określenia takich kierunków ich przemieszczania, które minimalizują globalne nakłady, związane z realizacją przewozów, uwzględniające dodatkowe ograniczenie typu zdolność przeróbcza stacji, zdolność przepustowa linii itp. Dotychczasowe rozwiązania zadania wyboru marszrut optymalnych dla potoków ładunków są niedokładne i mało efektywne. Wielu badaczy zadanie to rozwiązało wykorzystując liniowe metody transportowe, a w szczególności algorytm poszukiwania najkrótszej ścieżki w sieci $[1,9,18]$. Tymczasem zadanie wyboru marszruty optymalnej dla potoków ładunków jest zadaniem bardziej złożonym, gdyż powinno uwzględniać nakłady zależne od rozmiarów tych potoków, a tym samym od samych marszrut, określonych odpowiednimi algorytmami $[11,19]$. Dodatkowo, w zadaniu wyboru marszruty, należy uwzględnić lokalne ograniczenia technologiczne, związane $\mathrm{z}$ wielkością potoku ładunków na poszczególnych stacjach, szlakach i w relacjach planu zestawienia.

Zadanie wyboru marszruty optymalnej można efektywnie rozwiązać, korzystając $\mathrm{z}$ naturalnej graficznej interpretacji sieci kolejowej. W charakterze modelu matematycznego rozważmy sieć transportowa, opisaną symetrycznym grafem ważonym $G(\{i\},\{i, j\})$, składającym się ze zbioru węzłów $\{i\}$ i zbioru łuków $\{(i, j)\}(i, j=\overline{1 ; m})$, gdzie $m$ - ogólna liczba węzłów w sieci. Ponumerujemy wszystkie łuki: $k=\overline{m+1 ; n}$, gdzie $n$ - ogólna liczba elementów sieci. Wtedy $(n-m)$ jest liczbą łuków, rozpatrywanych w danej chwili. Marszrutą (drogą zorientowaną łańcuchem) od węzła $i$ do węzła $j$ nazywamy ciagg następujących po sobie węzłów i łuków sieci, w którym każdy łuk jest incydenty $\mathrm{z}$ węzłem poprzedzającym i następującym po nim: $i=i_{1},\left(i_{1} \cdot i_{2}\right) ; i_{2}, \ldots, i_{r-1},\left(i_{r-1}, i_{r}\right), i_{r}=j$.
Ponumerujmy wszystkie marszruty od węzła $i$ do węzła $j$. Wtedy $S_{i j}^{\delta}-$ oznacza marszrutę z numerem $\delta\left(\delta=\overline{1 ; \delta_{i j}}\right)$, gdzie $\delta_{i j}$ - liczba marszrut z $i$ do $j$. Niech węzły i łuki grafu $G$ będą opisane liczbami charakteryzującymi nakłady, związane z przeróbką jednostki potoku ładunków. Długością $d\left(S_{i j}^{\delta}\right)$ marszruty $S_{i j}^{\delta}$ będziemy nazywać sumą nakładów związanych z wszystkimi jej elementami. Niech dana będzie macierz korespondencji potoków $N=\left\|N_{i j}\right\|$ w określonymprzedziale czasowym $\Delta T\left(N_{i j}>0 ; i, j=\overline{1 ; m}\right)$, gdzie $i$ - stacja nadania, $j$ - stacja przeznaczenia.

Oznaczmy przez $N_{i j}^{\delta}$ - wielkość części korespondencji $N_{i j}$ przemieszczonej po marszrucie $S_{i j}^{\delta}\left(\sum_{\delta=1}^{\delta_{i j}} N_{i j}^{\delta}=N_{i j}\right)$.

Funkcja celu w zadaniu wyboru marszruty dla potoków ładunków w transporcie kolejowym ma postać funkcji nakładów, odniesionych do wszystkich elementów (wierzchołków i łuków) sieci:

$$
\hat{F}=\sum_{i=1}^{n} f_{i}\left(N_{i}\right) \rightarrow \min _{\left\{N_{i}\right\}}
$$

gdzie: $f_{i}\left(N_{i}\right)$ - nieliniowa funkcja nakładów dotyczących $i$-tego elementu, $i=\overline{1, n} ; N_{i}$-obciążenie $i$ - tego elementu, składające się z części rozdzielanej $\tilde{N}_{i}$ i normatywnej $\hat{N}_{i}$ :

$$
N_{i}=\tilde{N}_{i}+\hat{N}_{i}
$$

$n$ - ogólna liczba elementów sieci występująca w modelu.

W obliczeniach, dotyczących korekty operatywnej planu zestawiania pociągów towarowych, 
funkcja celu $\hat{F}$ charakteryzuje sumaryczne nakłady wagono-godzin przeróbki wagonów. W zadaniu wyboru marszruty, funkcja ta określa sumaryczne nakłady eksploatacyjne, związane z przemieszczaniem wagonów przez szlaki i stacje.

W przypadku ogólnym, funkcja celu może przyjać następującą postać:

$$
\hat{F}=\sum_{i=1}^{n} N_{i} t_{i}\left(N_{i}\right) \rightarrow \min _{\left\{N_{i}\right\}}
$$

gdzie: $t_{i}\left(N_{i}\right)$ - zależność czasu obróbki jednostki potoku wagonów od obciążenia elementu sieci.

Funkcja celu (2) minimalizuje sumaryczny czas przemieszczania się wagonów po wszystkich marszrutach. Uwzględniając, że $\sum N_{i j}=$ const, funkcja (2) minimalizuje średni czas przemieszczania się jednego wagonu po danej marszrucie.

Uniwersalnym podejściem do rozwiązania złożonych zadań optymalizacji jest metoda dekompozycji [5], która pozwala zamienić złożone zadanie wyjściowe zbiorem prostych wzajemnie powiązanych zadań, koordynacja rozwiązań których, pozwala znaleźć rozwiązanie zadania wyjściowego. Przy zadanych wartościach $t_{i}\left(N_{i}\right)$ funkcja celu (2) staje się liniową i posiada rozwiązanie dokładne, otrzymane drogą idealnej dekompozycji na zbiór zadań wyboru najkrótszej drogi w grafie $G$, dla określonego potoku $N_{i j}$. Wybór marszruty dla potoku $N_{i j}$, przy nieliniowej funkcji nakładów $t_{i}\left(N_{i}\right)$, zależy od obciążenia elementów sieci, a tym samym od dołączanych strug wagonów. $\mathrm{W}$ tym przypadku zadanie dekompozycji staje się o wiele trudniejszym.

Dekompozycja nieliniowa funkcji (2) możliwa jest przy wykorzystaniu metod iteracyjnych. Należy przy tym podkreślić, że algorytmy iteracyjne nie gwarantują zbieżności dekompozycyjnego algorytmu rozwiązania zadania nieliniowego (2), w skończonej liczbie kroków.

W pierwszym etapie budowy algorytmu dekompozycji zadania (2), pominiemy ograniczenia, dotyczące rozdzielenia potoku.

Wówczas rozwiązanie zadania w sposób istotny się upraszcza, i funkcję celu można przedstawić w ekwiwalentnej postaci:

$$
\begin{aligned}
& F=F\left(\left\{N_{i}\left(S_{k l}^{\delta}\right)\right\}\right)=\sum_{i=1}^{n} N_{i} t_{i}\left(N_{i}\right)= \\
& \sum_{i=1}^{n}\left(\sum_{\delta, k, l} N_{i}\left(S_{k l}^{\delta}\right) t_{i}\left(\sum_{\delta, k . l} N_{i}\left(S_{k l}^{\delta}\right)\right)\right) \rightarrow \min _{N_{i}\left(S_{k l}^{\delta}\right)}
\end{aligned}
$$

gdzie: $N_{i}=\sum_{\delta, k, l} N_{i}\left(S_{k l}^{\delta}\right), N_{i}\left(S_{k l}^{\delta}\right)-$ potok wagonów z $k$ do $l$, przemieszczany po marszrucie $S_{k l}^{\delta}$ o numerze $\delta\left(\delta=\overline{1, \delta_{k l}}\right)$ i elemencie $i$.

Dla uproszczenia przyjmiemy, że obciążenie $i$ - tego elementu stanowi tylko rozdzielana część potoku wagonów, tj. $N_{i}=\tilde{N}_{i}, \hat{N}_{i}=0$, co nie narusza ogólności rozważań.

Minimalizację funkcji cele (3) dokonuje się przy następujących ograniczeniach, związanych $\mathrm{z}$ istotą rozpatrywanego zadania:

a) ograniczenie dotyczące nierozłączności poto$\mathrm{ku}$ :

$$
\begin{aligned}
& N_{i}\left(S_{k l}^{\delta}\right)=N_{j}\left(S_{k l}^{\delta}\right), \quad i, j \in S_{k l}^{\delta} ; \quad \delta=\overline{1, \delta_{k l}} \\
& k, l=\overline{1, n} ; \quad k \neq l
\end{aligned}
$$

b) ograniczenie dotyczące pełnej realizacji przewozów (wywozu i wwozu odpowiednio):

$$
\begin{array}{ll}
\sum_{\delta=1}^{\delta_{i j}} N_{i}\left(S_{i j}^{\delta}\right)=N_{i j} ; & i, j=\overline{1, n} ; \quad i \neq j \\
\sum_{\delta=1}^{\delta_{i j}} N_{j}\left(S_{i j}^{\delta}\right)=N_{i j} ; & i, j=\overline{1, n} ; \quad i \neq j
\end{array}
$$

c) ograniczenia związane $\mathrm{z}$ wartością dodatnią potoków:

$$
\begin{aligned}
& N_{i}\left(S_{k l}^{\delta}\right) \geq 0 ; \quad i=\overline{1, n} ; \quad \delta=\overline{1, \delta_{k l}} ; \\
& k, l=\overline{1, n} ; \quad k \neq l
\end{aligned}
$$

Do dekompozycji zadania $(3 \div 7)$ wykorzystamy klasyczny schemat dowodowy warunków tego zadania w obszarze rozwiązania optymalnego.

Niech $\left\{N_{i}^{*}\left(S_{k l}^{\delta}\right)\right\}$ będzie optymalnym rozwiązaniem zadania $(3 \div 7)$ a $\left\{\left(N_{i}^{*}\left(S_{k l}^{\delta}\right)+\Delta N_{i}\left(S_{k l}^{\delta}\right)\right)\right\}$ - rozwiązaniem dopuszczalnym, zawierającym się $\mathrm{w}$ obszarze rozwiązania optymalnego. Wtedy spełniona jest następująca nierówność:

$$
\begin{aligned}
& \Delta F\left(\Delta N\left(S_{k l}^{\delta}\right)\right)=F\left(\left\{N_{i}^{*}\left(S_{k l}^{\delta}\right)+\Delta N_{i}\left(S_{k l}^{\delta}\right)\right\}\right)- \\
& -F\left(\left\{N_{i}^{*}\left(S_{k l}^{\delta}\right)\right\}\right) \geq 0
\end{aligned}
$$

Fizyczny sens nierówności (8) jest taki, że dowolny rozkład potoku w sieci, przy rozwiązaniu optymalnym, nie zmniejsza wartości funkcji celu.

$$
\text { Jeżeli }\left\{\left(N_{i}^{*}\left(S_{k l}^{\delta}\right)+\Delta N_{i}\left(S_{k l}^{\delta}\right)\right)\right\} \text { jest rozwiąza- }
$$
niem dopuszczalnym, spełniającym warunki $(4 \div 7)$, to $\Delta N_{i}\left(S_{k l}^{\delta}\right)$ spełnia następujące zależności: 
$\Delta N_{i}\left(S_{k l}^{\delta}\right)=\Delta N_{j}\left(S_{k l}^{\delta}\right) ; \quad i, j \in S_{k l}^{\delta} ; \quad \delta=\overline{1, \delta_{k l}} ;$

$k, l=\overline{1, n} ; \quad k \neq l$

$\sum_{\delta=1}^{\delta_{i j}} \Delta N_{i}\left(S_{i j}^{\delta}\right)=0 ; \quad i, j=\overline{1, n} ; \quad i \neq j$

$\sum_{\delta=1}^{\delta_{i j}} \Delta N_{j}\left(S_{i j}^{\delta}\right)=0 ; \quad i, j=\overline{1, n} ; \quad i \neq j$

$\Delta N_{i}\left(S_{k l}^{\delta}\right) \geq 0$, jeżeli

$N_{i}\left(S_{k l}^{\delta}\right)=0 ; \quad i=\overline{1, n} ; \quad \delta=\overline{1, \delta_{k l}} ; \quad k, l=\overline{1, n} ;$

$k \neq l$

Uwzględniając wypukłość i różniczkowalność funkcji $F\left(\left\{\left(N_{i}^{*}\left(S_{k l}^{\delta}\right)+\Delta N_{i}\left(S_{k l}^{\delta}\right)\right)\right\}\right), \quad$ względem wszystkich zmiennych, można wykorzystać twierdzenie Taylora o wartości funkcji $\mathrm{w}$ otoczeniu punktu. Zazwyczaj, w zadaniach optymalizacyjnych korzysta się z trzech pierwszych członów szeregu Taylora. Dla funkcji $F\left(\left\{\left(N_{i}^{*}\left(S_{k l}^{\delta}\right)+\Delta N_{i}\left(S_{k l}^{\delta}\right)\right)\right\}\right)$, szereg Taylora ma postać:

$$
\begin{aligned}
& F\left(\left\{\left(N_{i}^{*}\left(S_{k l}^{\delta}\right)+\Delta N_{i}\left(S_{k l}^{\delta}\right)\right)\right\}\right)=F\left(\left\{N_{i}^{*}\left(S_{k l}^{\delta}\right)\right\}\right)+ \\
& \sum_{\substack{\delta, i, k, l \\
k \neq l}} \frac{\partial F\left(\left\{N_{i}^{*}\left(S_{k l}^{\delta}\right)\right\}\right)}{\partial N_{i}\left(S_{k l}^{\delta}\right)} \Delta N_{i}\left(S_{k l}^{\delta}\right)+R
\end{aligned}
$$

gdzie $R$ - jest resztą o małej wartości dodatniej, wynikającej z wypukłości funkcji $F$.

Jeżeli drugi człon szeregu Taylora zamienimy resztą Lagrange'a, to nierówność (8) przyjmie wartość:

$$
\Delta F\left(\Delta N_{i}\left(S_{k l}^{\delta}\right)\right)=\sum_{\substack{\delta, i, k . l \\ k \neq l}} \frac{\partial F\left(\left\{N_{i}^{*}\left(S_{k l}^{\delta}\right)+\Theta \Delta N_{i}\left(S_{k l}^{\delta}\right)\right\}\right)}{\partial N_{i}\left(S_{k l}^{\delta}\right)} \Delta N_{i}\left(S_{k l}^{\delta}\right) \geq 0
$$

gdzie $\Theta \in 0,1$.

Zauważmy, że $\frac{\partial F\left(\left\{N_{i}\left(S_{k l}^{\delta}\right)\right\}\right)}{\partial N_{i}\left(S_{k l}^{\delta}\right)}=\frac{d F\left({ }^{*} N_{i}\right)}{d N_{i}}$, gdzie $N_{i}$ - obciążenie $i$ - tej stacji.

Przy małych wartościach $\Delta N_{i}\left(S_{k l}^{\delta}\right)$ można pomijać człon $R$, i nierówność (8) przyjmie postać:

$$
\sum_{\substack{\delta, i, k, l \\ k \neq l}} \frac{d F\left(N^{*}\right)}{d N_{i}} \Delta N_{1}\left(S_{k l}^{\delta}\right) \geq 0
$$

Wykorzystując zależności $(9 \div 12)$, w wyrażeniu (13) wydzielimy te składowe, które związane są z nakładami różniczkowymi wzdłuż marszruty $S_{k l}^{\delta}\left(\delta=\overline{1, \delta_{k l}} ; k, l=\overline{1, n} ; k \neq l\right)$ :

$$
\sum_{\substack{\delta, k, l \\ k \neq l}}\left\{\Delta N_{k}\left(S_{k l}^{\delta}\right)\left(\sum_{i \in S_{k l}^{\delta}} \frac{d F\left(N_{i}\right)}{d N_{i}}\right)\right\} \geq 0
$$

Wydzielenie składowych nakładów różniczkowych, dotyczących marszrut $S_{k l}^{\delta}$ stanowi idealną podstawę do dekompozycyjnego algorytmu rozwiązania zadania wyjściowego.

W budowie algorytmu dekompozycji wykorzystamy potok $N_{k}^{*}\left(S_{k l}^{\delta}\right)>0$, który określa optymalną część korespondencji, odpowiadającej marszrucie $S_{k l}^{\delta}\left(\beta \in\left\{\overline{1, \delta_{k l}}\right\}\right)$. Ponieważ $N_{k}^{*}\left(S_{k l}^{\beta}\right)>0$, to $\mathrm{z}$ wynika:

$$
\Delta N_{k}\left(S_{k l}^{\beta}\right)=-\sum_{\substack{\delta=1 \\ \delta \neq \beta}}^{\delta_{k l}} \Delta N_{k}\left(S_{k l}^{\delta}\right)
$$

Wykorzystując równanie (16) doprowadzimy początkowo nierówność (15) do postaci:

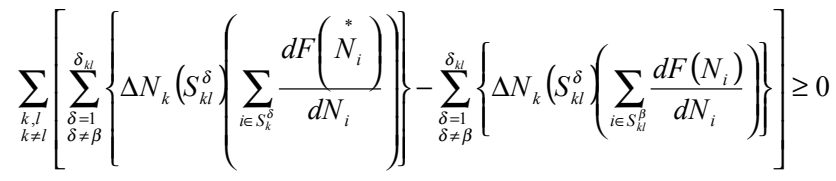

a następnie do postaci:

$\sum_{\substack{k, l \\ k \neq l}} \sum_{\substack{\delta \neq 1 \\ \delta \neq \beta}}^{\delta_{k \neq}} \Delta N_{k}\left(S_{k l}^{\delta}\right)\left(\sum_{i \in S_{k l}^{\delta}} \frac{d F\left(\stackrel{*}{N}_{i}\right)}{d N_{i}}-\sum_{i \in S_{k l}^{\beta}} \frac{d F\left(\stackrel{*}{N}_{i}\right)}{d N_{i}}\right) \geq 0$

Z zależności (12) wynika, że jeżeli $N_{k}^{*}\left(S_{k l}^{\delta}\right)=0$, to $\Delta N_{k}\left(S_{k l}^{\delta}\right) \geq 0$ i warunek:

$$
\sum_{\substack{i \in S_{k j}^{\delta} \\ \delta \neq \beta}} \frac{d F\left(\stackrel{*}{N}_{i}\right)}{d N_{i}} \geq \sum_{i \in S_{k l}^{\beta}} \frac{d F\left(\stackrel{*}{N}^{\beta}\right)}{d N_{i}}
$$

spełnia nierówność (17).

$$
\text { Jeśli }{ }^{*}\left(S_{k l}^{\delta}\right)>0 \text { to } \Delta N_{k}\left(S_{k l}^{\delta}\right) \text { może być do- }
$$
datnie lub ujemne. Wtedy nierówność (17) spełnia następujący warunek:

$$
\sum_{\substack{i \in S_{i l}^{\delta} \\ \delta \neq \beta}} \frac{d F\left(N^{*}\right)}{d N_{i}}=\sum_{i \in S_{k l}^{\beta}} \frac{d F\left(N^{*}\right)}{d N_{i}}
$$


Z wyrażenia (18) wynika, że $S_{k l}^{\delta}$ jest najkrótszą, ze względu na sumaryczne nakłady różniczkowe, marszrutą z punktu nadania do punktu przeznaczenia, zaś wyrażenie (19) dowodzi, iż przy optymalnym rozkładzie potoków, nakłady te powinny być jednakowe dla wszystkich marszrut potoku $N_{k l}$.

Tak więc, zadanie wyboru marszruty przy dopuszczalnym rozdrobnieniu potoku dekomponuje się na szereg prostych zadań poszukiwania najkrótszych odległości z $k$ do $l$ ze względu na nakłady, tj. $\min \sum_{i \in S_{k l}^{\delta}} \frac{d F\left(N_{i}\right)}{d N_{i}}$, gdzie $k, l=\overline{1, n}$.

Koordynacja tych zadań dokonywana jest z uwzględnieniem nieliniowych funkcji nakładów sumarycznych każdego elementu sieci, w zależności od jego obciążenia.

Dowodem na optimum rozwiązania jest powszechnie znany fakt, iż szczegółowe rozwiązanie optymalne wypukłej funkcji nieliniowej jest również rozwiązaniem ogólnym.

Nakłady różniczkowe można interpretować, jako koszty dodatkowe związane z przewozem ostatniego wagonu. Jeżeli na danej drodze suma nakładów różniczkowych jest większa niż na drodze innej, to dana marszruta nie jest optymalna, i dla zmniejszenia ogólnych nakładów należy ostatni wagon przemieszczać po innej marszrucie.

Uwzględniając strukturę funkcji celu (2) ogólne nakłady różniczkowe wzdłuż marszruty $S_{k l}^{\delta}$ mają postać:

$$
\sum_{i \in S_{k l}^{\delta}} \frac{d F\left(N_{i}\right)}{d N_{i}}=\sum_{i \in S_{k l}^{\delta}}\left[t_{i}\left(N_{i}\right)+N_{i} \frac{d t_{i}\left(N_{i}\right)}{d N_{i}}\right]
$$

Rozważmy sens fizyczny składowych wyrażenia (20). Niech $N_{i}[n]$ będzie obciążeniem $i$ - tej stacji w $n$-tym kroku wyboru marszruty, dla części $\Delta N_{k l}$ potoku $N_{k l}$. Wtedy pierwsza składowa $\sum_{i \in S_{k l}^{\delta}} t_{i}\left(N_{i}[n]\right)$ określa nakłady czasu na przemieszczanie potoku $N_{k l}$ wzdłuż marszruty $S_{k l}^{\delta}$ i pozwala ocenić efektywność przyłączenia $\Delta N_{k l}$ do danej marszruty, przy zadanych obciążeniach $N_{i}[n]$ elementów sieci. Obecność drugiej składowej $\sum_{i \in S_{k l}^{\delta}} N_{i}[n] \frac{d t_{i}\left(N_{i}[n]\right)}{d N_{i}}$ uwzględnia efekt nieliniowy, pojawiający się przy zmianie potoku w marszrucie $S_{k l}^{\delta}$. Tym samym, druga składowa pokazuje, w jaki sposób zmiana w obciążeniu marszruty $S_{k l}^{\delta}$ wpływa na przeróbkę pozostałych potoków i pozwala ocenić dodatkową efektywność przyłączenia $\Delta N_{k l}$ do danej marszruty. Efekt nieliniowy, wynikający $\mathrm{z}$ drugiej składowej równania (20), w sposób istotny utrudnia dekompozycję zadania $(3 \div 7)$. Jeżeli uwzględniać będziemy tylko pierwszą składową wyrażenia (20) to w każdym kroku rozkładu, potoki należy przydzielać do marszrut najkrótszych, wybranych przy zadanych obciążeniach $N_{i}[n]$ elementów sieci.

Optymalny rozkład potoku wagonów na sieci kolejowej powinien gwarantować równowagę, tj. najkrótsze w sensie nakładów różniczkowych, marszruty od punktów nadania do punktów przeznaczenia. Spostrzeżenie to stanowi podstawę algorytmów wyboru marszrut dla potoków wagonów.

\section{Literatura}

[1] Акулиничев В.М. и др.: Организачия вагонопотоков и маршрутизащия перевозок, М., «Транспорт»,1970

[2] Cisowski T.: Metodyka wyboru dróg przewozu tadunków w transporcie kolejowym. Pojazdy Szynowe, $\mathrm{Nr}$ $3 / 2008$

[3] Gajda B.: Technologia i automatyzacja pracy stacji, Wydawnictwo Politechniki Warszawskiej, 1983

[4] Gutenbaum J.: Modelowanie matematyczne systemów, PWN, Warszawa-Łódź, 1987

[5] Кутыркин А.В., Кадушин А.И.: Декомпозиционный алгоритм регулирования порожних вагонопотоков в АСУЖТ, М., «Транспорт», «Вестник ВНИИЖТ», №6,1978

[6] Кутыркин А.В.: Динамическая модель планирования и оперативного управления вагонопотоками, «Вестник ВНИИЖТ》, №8,1981

[7] Лебедев Т.П., Ломакина Н.Н., Садиков П.П., Сотников Е.А.: Расчет времени нахождения вагонов на сортировочных и участковых станциях, Труды ЦНИИ МПС, выгn. 481, «Транспорт», 1973

[8] Leszczyński J.: Optymalna decyzja w procesach transportowych, WKiK, Warszawa, 1981

[9] Leszczyński J.: Modelowanie systemów i procesów transportowych, Wydawnictwo Politechniki Warszawskiej, Warszawa, 1990

[10]Лебедев Т.П., Ломакина Н.Н., Садиков П.П., Сотников Е.А.: Расчет времени нахождения вагонов на сортировочных и участковых станциях, Труды ЦНИИ МПС, вып. 481, «Транспорт», 1973

[11]Левит Б.Ю., Лившии В.Н.:Нелинейные сетевые транспортные задачи, М., «Транспорт», 1972

[12]Nowosielski L.: Procesy przewozowe w transporcie kolejowym, Oficyna Wydawnicza Politechniki Warszawskiej, Warszawa, 1995

[13]Nowosielski L.: Organizacja przewozów kolejowych, Kolejowa Oficyna Wydawnicza, Warszawa, 1999

[14]Potthoff G.: Teoria potoków ruchu, WKiK, Warszawa, 1973

[15]Steenbrick P.A.: Optymalizacja sieci transportowych, WKiK, Warszawa 1978

[16]Systo M., Deo N., Kowalik J.S.: Algorytmy optymalizacji dyskretnej, PWN, 1985

[17]Woch J.: Podstawy inżynierii ruchu kolejowego, WKiK, Warszawa, 1983

[18]Wyrzykowski W.: Ruch kolejowy, WKiK, Warszawa 1967 